\title{
PENGEMBANGAN MEDIA PEMBELAJARAN QUR'AN HADIST DENGAN MAGIC DISC TAJWID
}

\author{
Fauzan Zulkarnain ${ }^{1}$, Rijal Firdaos ${ }^{2}$, Heru Juabdin Sada ${ }^{3}$ \\ herujuabdin@ radenintan.ac.id \\ Universitas Islam Negeri Raden Intan Lampung ${ }^{1,2,3}$
}

\begin{abstract}
This study aims to develop the medium of Tajweed learning magic disc in the Qur'anic lessons of Hadith. The method used in this research is research and development (research and development). This study adopts the theory of Borg and Gall using 7 steps in the study. The data analysis technique used in the research is quantitative descriptive analysis technique. This research and development resulted in a product in the form of learning media magic disc tajwid non dead material or disk-shaped tanwin that can be used. The assessment was obtained from (1) the media expert validator got a score of $75.1 \%$ (2) the material expert validator got a score of 79\%. For the assessment of the responses of students in field trials conducted on a small scale get a percentage rating of $83 \%$, and field trials on a large scale get a percentage rating of 95\% which means that the learning media of magic disc Tajweed effectively used to be able to increase motivation, student interest in learning and make students more active in learning.
\end{abstract}

Keywords: Media development, magic disc, tajwid

\begin{abstract}
Abstrak
Penelitian bertujuan untuk mengembangkan media pembelajaran magic disc tajwid pada mata pelajaran Al-Qur'an Hadist. Metode penelitian ini adalah penelitian dan pengembangan R\&D (Research And Development). Penelitian ini mengadopsi teori dari Borg and Gall dengan menggunakan 7 langkah dalam penelitian. Teknik analisis data dalam penelitian ini yaitu dengan teknik deskriptif kuantitatif. Penelitian dan pengembangan ini menghasilkan produk berupa media pembelajaran magic disc tajwid materi pada pokok bahasan nun mati atau tanwin yang berbentuk piringan yang dapat digunakan. Penilaian tersebut didapatkan dari (1) validator ahli media mendapatkan nilai sebesar $75,1 \%$ (2) dari validator ahli materi mendapatkan nilai sebesar 79\%. Untuk penilaian tanggapan dari peserta didik pada uji coba lapangan yang dilakukan pada skala kecil mendapatkan penilaian persentase sebesar $83 \%$, dan uji coba lapangan pada skala besar mendapatkan penilaian persentase sebesar $95 \%$ yang mana berarti bahwasanya media pembelajaran magic disc tajwid efektif digunakan untuk dapat meningkatkan motivasi, minat belajar peserta didik dan membuat peserta didik lebih aktif dalam belajar.
\end{abstract}

Kata Kunci: pengembanga media, magic disc, tajwid 


\section{PENDAHULUAN}

Perkembangan teknologi dan informasi ini banyaknya perubahan mengenai cara pandang tentang pendidikan (Budiman, 2017). Berkembangnya teknologi informasi tersebut berdampak pada proses pendidikan (Masykur, Nofrizal, and Syazali, 2017). Banyaknya sumber pengetahuan akan memunculkan metode pembelajaran yang baru guna memanuhi kebutuhan fasilitas-fasilitas yang digunakan dalam hal pembelajaran. Pendidik dituntut untuk dapat mendidik peserta didik agar mampu menghadapi perkembangan, permasalahan dan menggunakan teknologi yang berkembang pada saat ini untuk mendukung dalam hal pendidikan (Kartilawati and Warohmah, 2014). Sistem teknologi dan informasi yang dibutuhkan dalam peningkat kapasitas pendidikan tidak hanya sebagai sarana penunjang saja, namun sebagai alat penting dalam menunjang kesuksesan dalam dunia pendidikan agar dapat bersaing di pasar global (Budiman, 2017).

Didalam pendidikan, banyak usaha yang dilakukan untuk memperbaharui atau menginovasi tentang pendidikan. Pembaharuan dalam hal pendidikan tersebut contohnya adalah manejemen pendidikan, metode pendidikan, media pembelajaran, sumber- sumber belajar, kurikulum pendidikan, dan masih banyak hal yang dilakukan untuk melakaukan pembaharuan mengenai pendidikan. Berdasarkan pendapat tersebut dapat dipahami bahwa melalui media pembelajaran, aktivitas, kreativitas dan motivasi peserta didik dalam pembelajaran dapat ditingkatkan, penyampaian materi pelajaran dapat dipermudah dengan adanya media pembelajaran sebagai penunjang dalam penyampaian materi. Menurut Gerlach dan Elly mengatakan bahwa media adalah kejadian yang bersifat membangun sebuah kondisi dan membuat peserta didik memperoleh pemahaman ilmu, sikap dan keterampilan (Azhar Arsyad, 2015). Media merupakan suatu instrumen yang dapat dimanipulasikan, ditinjau, didengarkan, dan dilafalkan. Media pembelajaran menjadi salah satu unsur sumber belajar yang penting untuk digunakan. Keberadaan media pembelajaran ini dapat menentukan kesuksesan pembelajaran (Astuti, Sumarni, and Saraswati, 2017). Media pembelajaran sendiri merupakan campuran antara bahan untuk belajar dan alat untuk belajar (Muhson, 2010).

Dasar pertimbangan utama dalam menyesaikan media pembelajaran peserta didik yang akan menjadi peran penting. karena ketiadaan media pembelajaran yang 
menunjang setiap jenjang usia. Barbara B. Seels menjelaskan perlunya informasi terkait dengan gaya belajar atau learning style. Sehingga sebuah perancangan yang baik sangat penting agar tepat sasaran dalam penggunaannya.(Cepi Riyana \& Rudi Susilana, 2009) Khususnya Pada pembelajaran Pendidikan Agama Islam menggunakan media pembelajaran yang disarankan untuk mengembangkan pembelajaran, agar bisa memahami materi dan menyampaikan materi yang di sampaikan kepada peserta didik (Lukman Hakim, 2018). Salah satu solusi media pembelajaran yang dapat mengatasi permasalahan di atas adalah Magic Disc. Magic disc merupakan media pembelajaran yang mempunyai fungsi spesifik yaitu pelafalan atau pemahaman simbol-simbol, namanama atau kata asing, rata-rata hasil pelajaran Bahasa Inggris meningkat selesainya diberi model dengan memakai permainan bingo juga Magic disc secara berulang-ulang.. Magic disc juga sudah banyak diperbarui dalam berbagai bentuk. Magic disc merupakan salah satu media yang lebih mudah digunakan dalam pembelajaran, karena dapat memberikan informasi secara terampil dan efisien (Satria, Hamidah, dan Yelianti, 2019.) Penelitian Kusrini menjelaskan bahwa penggunaan media audiovisual Magic Disc bisa menaikkan memotivasi peserta didik secara signifikan pada mengusut bahasa. (Hermawan Setya Budi, 2010).

Salah satu ilmu yang harus dipelajari adalah ilmu tajwid. Ilmu tajwid adalah ilmu tentang tata cara membaca Al-Qur'an dengan baik dan benar (Septiawan, 2012). Hal ini sangat penting dikarenakan belajar Al-Qur'an merupakan prioritas utama manusia sebelum mempelajari ilmu pengetahuan yang lain (Permatasari and Falah, 2015). Namun, berdasarkan hasil wawancara kepada pendidik di Mts Negeri 1 Lampung tengah bahwa pada mata pelajaran qur'an hadits, penggunaan media pembelajaran terkait pelajaran tersebut belum banyak digunakan pada proses pembelajaran. Metode pembelajaran yang digunakan juga masih berupa metode ceramah, praktik membaca Al-Qur'an serta pembelajaran kelompok yang membuat peserta didik kebanyakan merasa bosan dalam menerima materi pelajaran. Dilihat dari fakta tersebut, maka dibuat media pembelajaran yaitu Magic Disc Tajwid.

Karakteristik menurut Magic Disc Tajwid merupakan memiliki ciri visual cetak yang sangat mudah diaplikasikan dan mudah buat peserta didik. Berdasarkan penerangan tentang definisi menurut magic disc diatas, dapat dipahami bahwa media 
pembelajaran bias dijadikan sebagai alat yang mampu membantu peserta didik pada memahami materi pelajaran, dimana media magic disc ini mempunyai dua sisi, antara lain: sisi lingkaran dan persegi.Sedangkan ciri dari media magic disc tajwid artinya: (1) Sisinya yang berbeda. (2) definisi mengenai aturan tajwid nun mangkat atau tanwin terdapat dalam sisi lingkaaran. (3) berita rona, alfabet hijaiyah dan model- model menurut bacaan setiap aturan tajwid nun mangkat atau tanwin dijelaskan dalam sisi persegi. (4) Terdapat makna yang berbeda- beda dalam setiap rona pada lingkaran. (5) Penggunaannya yang praktis \& gampang. Berdasarkan penjelasan pada atas, maka tujuan menurut penelitian ini adalah membuatkan media pembelajaran magic disc tajwid pada pelajaran al-qur'an hadist.

\section{METODE PENELITIAN}

Jenis penelitian ini menggunakan penelitian dan pengembangan (Researh and Development). Metode yang digunakan dalam mengembangkan atau menvalidasi produk- produk yang digunakan dalam pendidikan dan pembelajaran. Metode Borg and Gall digunakan dan telah dimodifikasi oleh Sugiyono untuk mengembangkan dan menvalidasi produk produk yang dikembangkan. Dalam metode penelitian ini memiliki 7 langkah dalam pelaksanaannya, yaitu potensi dan masalah, pengumpulan data, desain produk, validasi desain, perbaikan desain, uji coba produk, dan revisi produk (Sugiyono, 2013).

Berikut langkah-langkah penelitian oleh peneliti:

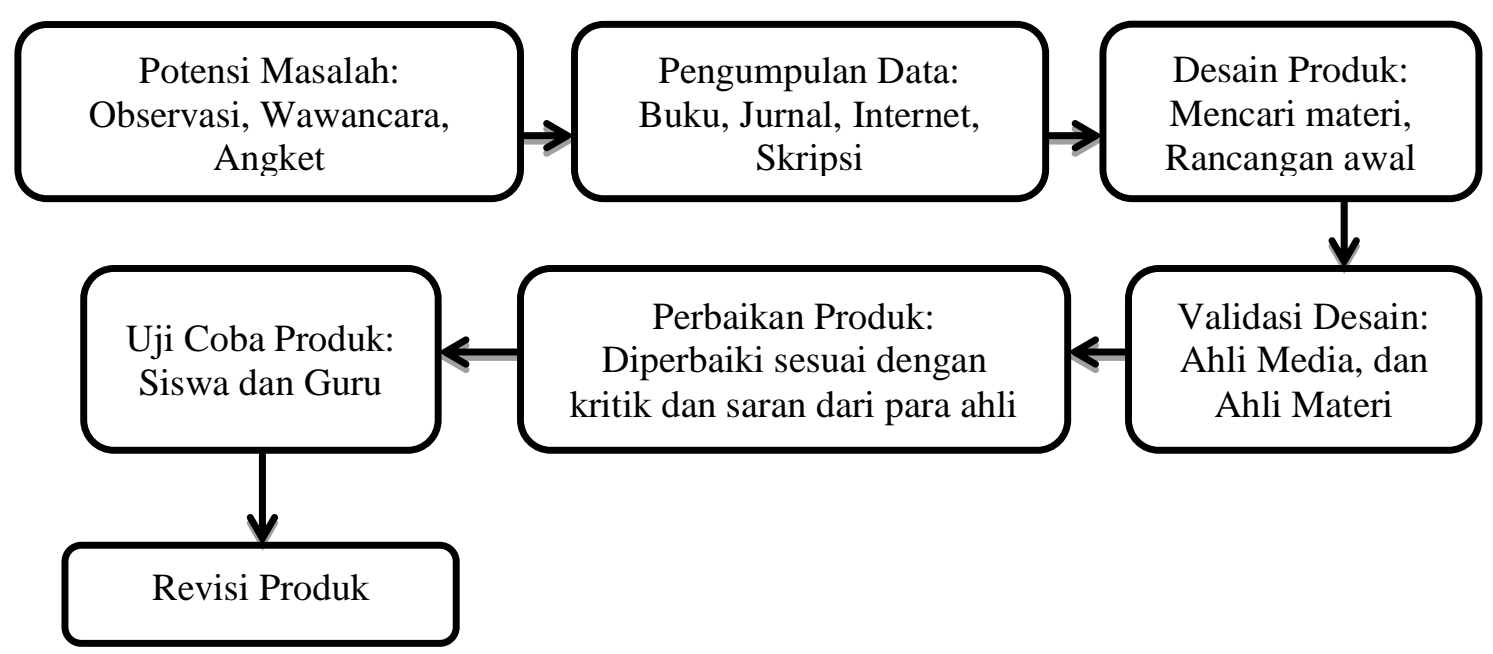

Gambar 1. Prosedur Penelitian Yang Digunakan 
Pada data hasil dari penelitian ini menunjukkan bahwa data Kulitatif dan Kuantitatif. Kuantitatif merupakan skor dari penilaian yang terdapat pada lembar angket yang berupa validator ataupun pengguna. Data kualitatif adalah data yang dapat berupa kritik dan saran validator dan pengguna terhadap media magic disc yang dikembangkan.

Pada perhitungan data kuantitatif pada sebuah angket, analisasi data yang digunakan adalah presentase dengan nilai masing- masing aspek dengan rumus berikut:

$$
X_{1}=\frac{\sum S}{S_{\max }} \times 100 \%
$$

Keterangan:

$$
\begin{array}{ll}
X_{1} & =\text { Nilai kelayakan angket } \\
\sum S & =\text { Jumlah skor } \\
S_{\max } & =\text { Skor maximal }
\end{array}
$$

Pengertian dari Skala likert adalah skala yang dapat menjelaskan suatu jenjang/ tingkat kekuatan dari sebuah pernyataan persetujuan (setuju dan tidak setuju). Ada beberapa alasan bagi peneliti menggunakan skala likert, diantaranya: 1) Memberikan kemudahan kepada responden dalam menjawab kuisioner apakah setuju atau tidak setuju. 2) Lebih mudah digunakan sehingga mudah dipahami oleh responden. 3) Tampilan skala likert yang menarik dan memudahkan responden dalam mengisinya. Peneliti menggunakan skala likert 5 poin yang terdiri dari "Sangat Baik", "Baik", “Cukup”, “Kurang”, “Sangat Kurang” pada penelitian ini (Sugiyono, 2013).

Tabel 1. Kriteria Penilaian Skala Likert

\begin{tabular}{|l|c|c|}
\hline \multicolumn{1}{|c|}{ Kategori } & Nilai & Persentase \\
\hline SB (Sangat baik) & 5 & $80 \%-100 \%$ \\
\hline B (Baik) & 4 & $60 \%-79 \%$ \\
\hline C (Cukup) & 3 & $40 \%-59 \%$ \\
\hline K (Kurang) & 2 & $20 \%-39 \%$ \\
\hline SK (Sangat Kurang) & 1 & $0 \%-19 \%$ \\
\hline
\end{tabular}


Aplikasi microsoft excel 2010 digunakan untuk membantu dalam perhitungan data yang dihasilkan, setelah itu nilai rata-rata yang diperoleh akan menjadi nilai kualitatif berdasarkan ketentuannya. Persentase kelayakan hasil penilaian produk magic disc dapat ditunjukkan melalui table skala likert yang digunakan sebagai suatu media pembelajaran yang digunakan.

\section{HASIL PENELITIAN DAN PEMBAHASAN}

Media pembelajaran magic disc tajwid setelah selesai dibuat kemudian divalidasi oleh validator desain media dan validator materi. Pertama media divalidasi oleh validator desain media dan memperoleh hasil sebagai berikut:

Tabel 2. Validasi Media Tahap Pertama

\begin{tabular}{|c|l|c|c|c|}
\hline No & Kriteria Penilaian & $\begin{array}{c}\text { Skor rata- } \\
\text { rata }\end{array}$ & Persentase & Kriteria \\
\hline 1 & Tampilan khusus & 3,5 & $70 \%$ & Layak \\
\hline 2 & Tampilan umum & 3,3 & $67 \%$ & Layak \\
\hline 3 & Penyajian media & 3,5 & $70 \%$ & Layak \\
\hline \multicolumn{2}{|c|}{ Rata- rata keseluruhan } & 3,4 & $69 \%$ & Layak \\
\hline
\end{tabular}

Berdasarkan tabel 2 diatas dapat diketahui dengan nilai rata- rata seluruhan dari penilaian validasi ahli media itu adalah sebesar $69 \%$ yang dapat dikategorikan layak. Selanjutnya media direvisi, yaitu pada bagian memperbesar media magic disc tajwid serta penambahan praktik membaca sebagai tolak ukur keberhasilan belajar peserta didik. Kemudian dilakukan validasi media tahap kedua yang memperoleh hasil sebagai berikut:

Tabel 3. Validasi Tahap Kedua

\begin{tabular}{|c|l|c|c|c|}
\hline No & Kriteria Penilaian & $\begin{array}{c}\text { Skor rata- } \\
\text { rata }\end{array}$ & Persentase & Kriteria \\
\hline 1 & Tampilan khusus & 4,08 & $82 \%$ & Sangat Layak \\
\hline 2 & Tampilan umum & 4 & $80 \%$ & Sangat Layak \\
\hline 3 & Penyajian media & 4,25 & $85 \%$ & Sangat Layak \\
\hline \multicolumn{2}{|c|}{ Rata- rata keseluruhan } & 4,11 & $82 \%$ & Sangat Layak \\
\hline
\end{tabular}


Berdasarkan tabel 3 tersebut muncul skor rata- rata seluruhan dari penilaian media adalah $82 \%$ yang dapat dikategorikan sangat layak digunakan. Kedua, media divalidasi oleh validator materi dengan hasil validasi tahap pertama sebagai berikut:

Tabel 4. Validasi Materi Tahap Pertama

\begin{tabular}{|c|l|c|c|c|}
\hline No & Kriteria Penilaian & $\begin{array}{c}\text { Skor rata- } \\
\text { rata }\end{array}$ & Persentase & Kriteria \\
\hline 1 & Kelayakan Isi & 3,9 & $78 \%$ & Layak \\
\hline 2 & Materi & 4 & $80 \%$ & Layak \\
\hline 3 & Bahasa & 3,6 & $72 \%$ & Layak \\
\hline \multicolumn{2}{r|}{ Rata- rata } & 3,8 & $77 \%$ & Layak \\
\hline
\end{tabular}

Dari keseluruhan aspek dapat kita ketahui bahwasanya mean dari ketiga aspek kelayakan materi tersebut adalah $77 \%$ termasuk dalam katagori layak. Materi pada media selanjutnya agar penempatan warnanya tepat karena bersesuaian dengan kerapihan dan kejelasan pada pengertian tiap hukum tajwid. Media yang telah direvisi selanjutnya divalidasi materi tahap kedua dengan hasil sebagai berikut:

Tabel 5. Validasi Materi Tahap Kedua

\begin{tabular}{|c|l|c|c|c|}
\hline No & \multicolumn{1}{|c|}{ Kriteria Penilaian } & $\begin{array}{c}\text { Skor rata- } \\
\text { rata }\end{array}$ & Persentase & Kriteria \\
\hline 1 & Kelayakan Isi & 4,3 & $86 \%$ & Sangat Layak \\
\hline 2 & Materi & 4 & $80 \%$ & Sangat Layak \\
\hline 3 & Bahasa & 4 & $80 \%$ & Sangat Layak \\
\hline \multicolumn{2}{|c|}{ Rata- rata } & 4,1 & $82 \%$ & Sangat Layak \\
\hline
\end{tabular}

Berdasarkan tabel 5 diatas dapat kita ketahui bahwa mean dari seluruh dari aspek kelayakan materi sebesar $82 \%$ termasuk dalam kategori sangat layak. Media yang sudah divalidasi baik desain dan materinya, kemudian diuji cobakan pada kelompok kecil dengan hasil sebagai berikut: 
Tabel 6. Uji Coba Kelompok Kecil

\begin{tabular}{|c|c|c|c|c|}
\hline No & Kriteria Penilaian & $\begin{array}{c}\text { Skor rata- } \\
\text { rata }\end{array}$ & Persentase & Kriteria \\
\hline 1 & Tampilan & 4,3 & $88 \%$ & Sangat Baik \\
\hline 2 & Materi & 4 & $80,3 \%$ & Sangat Baik \\
\hline 3 & Manfaat & 4,1 & $82,2 \%$ & Sangat Baik \\
\hline \multicolumn{2}{|r|}{ Rata- rata } & 4,1 & $83 \%$ & Sangat Baik \\
\hline
\end{tabular}

Berdasarkan tabel 6 di atas dapat diketahui bahwasanya nilai rata- rata dari ketiga penilaian berkategori sangat layak dengan. Peserta didik saat uji coba kelompok kecil merespon dan antusias terhadap media magic disc sangat baik. Kemudian dilanjutkan uji coba media pada kelompok besar dengan hasil sebagai berikut:

Tabel 7. Uji Coba Kelompok Besar

\begin{tabular}{|c|c|c|c|c|}
\hline No & Aspek Yang Dinilai & $\begin{array}{c}\text { Skor rata- } \\
\text { rata }\end{array}$ & Persentase & Kriteria \\
\hline 1 & Tampilan & 4,8 & $96 \%$ & Sangat Baik \\
\hline 2 & Materi & 4,8 & $96 \%$ & Sangat Baik \\
\hline 3 & Manfaat & 4,7 & $94 \%$ & Sangat Baik \\
\hline \multicolumn{2}{|c|}{ Rata- rata keseluruhan aspek } & 4,8 & $95 \%$ & Sangat Baik \\
\hline
\end{tabular}

Berdasarkan tabel 7 diatas dapat disimpulkan bahwasanya nilai rata- rata dari ketiga aspek tersebut sebesar 95\% termasuk dalam kategori sangat layak, sehingga dapat disimpulkan bahwa pengembangan media pembelajaran magic disc tajwid sangat bisa dipakai dan mendapatkan respon yang positif dari para peserta didik, sehingga dapat digunakan sebagai media dalam proses pembelajaran, dan memotivasi peserta didik untuk lebih giat dalam belajar, membuat peserta didik selalu aktif dan inovatif dalam belajar, dan pendukung dalam menyampaikan materi yang diberikan oleh seorang pendidik. Hal tersebut dibuktikannya dengan adanya hasil angket yang diajukan kepada para validator ahli media dan materi, serta peserta didik sebagai responden dalam pengujian pengembangan media magic disc tajwid. 


\section{SIMPULAN DAN SARAN}

Peneliti memperoleh beberapa konklusi menurut analisasi data pada penelitian ini. Kedua, Dari hasil validasi atau penilaian yang dilakukan oleh tim validator media dan materi dapat disimpulkan bahwa media pembelajaran magic disc tajwid materi nun mati (sukun) atau tanwin ini dapat dikatakan layak digunakan menjadi media pembelajaran pada Madrasah Tsanawiyah Negeri 1 Lampung Tengah. Ketiga, Media pembelajaran magic disc tajwid materi nun mati (sukun) atau tanwin memperoleh respon yang sangat baik menurut para peserta didik. Peneliti mengharapkan kepada peneliti selanjutnya yang ingin mengambil penelitian yang sama dengan penelitian ini agar dapat berbagi materi tajwid lainnya yang lebih banyak, sebagai akibatnya lebih komprehensif output produknya. 


\section{DAFTAR PUSTAKA}

Astuti, Irnin Agustina Dwi, et al. "Pengembangan Media Pembelajaran Fisika Mobile Learning Berbasis Android." Jurnal Penelitian Dan Pengembangan Pendidikan Fisika, vol. 3, no. 1, 2017, pp. 57-62.

Azhar Arsyad. Media Pembelajaran. Cet. 18, PT Rajagrafindo Persada, 2015, p. 4.

Budiman, Haris. "Peran Teknologi Informasi Dan Komunikasi Dalam Pendidikan.” AlTadzkiyyah: Jurnal Pendidikan Islam, vol. 8, no. 1, 2017, p. 31, doi:10.24042/atjpi.v8i1.2095.

Hakim, Lukman. "Pengembangan Media Pembelajaran PAI Berbasis Augmented Reality." Jurnal Lentera Pendidikan Universitas Nurul Jadid, vol. Vol. 20, no. No. 1, 2018, p. 60.

Hermawan Setya Budi. "Keefektifan Media Cakram Ajaib Dan Metode Koorperatif Tipe Co-Op Co-Op Pada Pembelajaran Sistem Pencernaan Manusia Di SMP Negeri 30 Semarang." Skripsi Program Sarjana Fakultas Matematika Dan Ilmu Pengetahuan Alam, Universitas Negeri Semarang, 2010, p. 9.

Kartilawati, Mawaddatan Warohmah, "Profesionalisme Pendidik Pendidikan Agama Islam di Era Teknologi Informasi dan Komunikasi." Ta'dib, vol. 19, no. 01, pp. 143-167.

Masykur, Rubhan, et al. "Pengembangan Media Pembelajaran Matematika Dengan Macromedia Flash." Al-Jabar : Jurnal Pendidikan Matematika, vol. 8, no. 2, 2017, p. 177, doi:10.24042/ajpm.v8i2.2014.

Muhson, Ali. "Pengembangan Media Pembelajaran Berbasis Teknologi Informasi." Jurnal Pendidikan Akuntansi Indonesia, vol. 8, no. 2, 2010, pp. 1-10.

Permatasari, Deasy, and Andri Falah. "Aplikasi Pembelajaran Ilmu Tajwid Berbasis Android (Studi Kasus : Madrasah Ar-Rahman Bandung)." Jurnal Teknologi Dan Informasi UNIKOM, vol. 1, no. 7, 2015, pp. 2088-270.

Rudi Susilana, Cepi Riyana. Media Pembelajaran Hakikat, Pengembangan, Pemanfaatan, Dan Penilaian. CV Wacana Prima, 2009.

Satria, Andreo, et al. "Pengembangan Magic Disc Pada Bahan Taksonomi Hewan Untuk Peserta didik SMA." Biodik: Jurnal Ilmiah Pendidikan Biologi, vol. 5, no. 3, 2019, pp. 2460-612.

Septiawan, Arif Tri. "Pengenalan Dan Pembelajaran Cara Membaca Al-Qur'an (Ilmu Tajwid) Berbasis Mobile Android." Electronic Thesis and Dissertations Universitas Muhammadiyah Surakarta, 2012.

Sugiyono. Metode Penelitian Kuantitatif Kualitatif Dan R\&D. Alfabeta, 2007. 